\section{Differences in Inflorescence Numbers and Endogenous Gibberellic Acid Levels in 'Afterglow' Bougainvillea}

\author{
Mun Wye Chng ${ }^{1}$ and Kimberly A. Moore ${ }^{2}$
}

ADDITIONAL INDEX wORDs. abscisic acid, ethephon, ethylene, photoperiod, plant growth regulator

Summary. Bougainvillea (Bougainvillea sp.) plant inflorescence number will vary in response to multiple cues such as changes in temperature, water, light intensity, pruning, and photoperiod. Previous research reports that the application of plant growth regulators (PGRs) to bougainvillea grown under varying photoperiods improved inflorescence number, probably as a result of changes in gibberellic acid (GA) levels. There are many bioactive plant GAs, but we chose to investigate differences in gibberellic acid $3\left(\mathrm{GA}_{3}\right)$ levels and inflorescence number in response to the application of ethephon (2-cholorethylphosponic acid) or abscisic acid (ABA) to 'Afterglow' bougainvillea (Bougainvillea $\times$ buttiana) grown under 14-hour photoperiod [long-day (LD)] conditions. Plants were 5 inches tall with seven visible lateral nodes and were grown in a greenhouse in 4-inch pots filled with 5 - $\mathrm{mm}$ coarse aquarium zeolite. Ethephon was applied as a foliar spray at $0.05,0.07,0.10,0.15$, or $0.20 \mathrm{mg} /$ plant. ABA was applied as a soil drench at $1,1.5,3,6,8$, or $10 \mathrm{mg}$ / plant. Endogenous levels of $\mathrm{GA}_{3}$ were measured 1 and 48 days after treatment to calculate the change in $\mathrm{GA}_{3}\left(\Delta \mathbf{G A}_{3}\right)$. A short day (SD) control of 8 hours was included to measure differences in inflorescence number and $\triangle \mathbf{G A}_{3}$ between photoperiods. 'Afterglow' plants grown under SD conditions had the greatest decrease in $\Delta \mathrm{GA}_{3}\left(-1.09 \mu \mathrm{g} \cdot \mathrm{g}^{-1}\right)$ over 48 days and the most inflorescences $(10.6)$ compared with LD control plants with a decrease in $\Delta \mathrm{GA}_{3}$ of $-0.09 \mu \mathrm{g} \cdot \mathrm{g}^{-1}$ and fewer inflorescences (1.0). Plants grown under LD conditions and treated with $0.05 \mathrm{mg} /$ plant ethephon had inflorescence numbers (9.6) and levels of $\Delta \mathrm{GA}_{3}\left(-0.74 \mu \mathrm{g} \cdot \mathrm{g}^{-1}\right)$ similar to the SD control. As ethephon rate increased to more than $0.05 \mathrm{mg} /$ plant, inflorescence number on $L D$ plants decreased and $\triangle G A_{3}$ increased. Exogenous $A B A$ rates of 1 $\mathrm{mg} /$ plant produced inflorescence numbers (1.4) and $\Delta \mathrm{GA}_{3}\left(-0.10 \mu \mathrm{g} \cdot \mathrm{g}^{-1}\right)$ similar to the LD control. As the rate increased, $\triangle G A_{3}$ increased and inflorescence number decreased. Plants treated with $\mathrm{ABA}$ rates of $3 \mathrm{mg} / \mathrm{plant}$ and more were defoliated and had no inflorescences.

$\mathrm{B}$ ougainvillea (Bougainvillea sp.) is a popular landscape ornamental plant in tropical and subtropical zones around the world, valued for its vigor and relative resistance to pests, disease, and drought;

Received for publication 12 June 2020. Accepted for publication 27 Aug. 2020.

Published online 25 September 2020

${ }^{1}$ National Parks Board, 70 River Valley Road, \#01-05, Singapore, 179037

${ }^{2}$ University of Florida, Institute of Food and Agricultural Sciences, Fort Lauderdale Research and Education Center, 3205 College Avenue, Davie, FL 33314

We thank Andy Fu, Luci Fisher, and Ragab Salama for technical assistance. FTL-FLA 005829.

This work was completed as part of a $\mathrm{PhD}$ program in environmental horticulture at the University of Florida, Institute of Food and Agricultural Sciences, Fort Lauderdale Research and Education Center.

K.A.M. is the corresponding author. E-mail: klock@ ufl.edu.

This is an open access article distributed under the CC BY-NC-ND license (https://creativecommons.org/ licenses/by-nc-nd/4.0/).

https://doi.org/10.21273/HORTTECH04673-20 variability in form; and bright floral display of colorful bracts. Inflorescences form in apical panicles on the current year's wood, with number of inflorescences and timing of flowering varying based on differences in cultivars as well as in response to changes in temperature, irrigation, light intensity, pruning, and photoperiod (Hackett and Sachs,
1985; Norcini et al., 1994). 'Afterglow' bougainvillea (Bougainvillea $\times$ buttiana) plants grown under SDs $(8 \mathrm{~h})$ had visible inflorescences within $30 \mathrm{~d}$, with 8 to 10 inflorescences per plant compared with no inflorescences on LD (14-h) plants after $30 \mathrm{~d}$ (Chng and Moore, 2016).

Inflorescence number on bougainvillea plants grown under LD conditions has been enhanced by the use of PGRs such as chlormequat, daminozide, paclobutrazol, and dikegulac, which act by inhibiting GA levels (Karagüzel, 1999; Liu and Chang, 201 lb; Norcini et al., 1994). Gibberellic acids play an important role in flowering pathways (CamposRivero et al., 2017; Taiz et al., 2018). They promoted flowering in LD plants such as spinach [Spinacia oleracea (Metzger and Zeevaart, 1980)], and sweet william [Silene armeria (Talon and Zeevaart, 1990)], but exogenous applications of GA to 'San Diego Red' bougainvillea grown under SD conditions inhibited flowering (Even-Chen et al., 1979).

Hackett and Sachs (1985) suggested that GAs stimulate sinks for available plant resources that compete with developing inflorescence primordia, and the removal of young leaves reduces GA levels, potentially shifting resources to inflorescences (Hackett and Sachs, 1985). Gibberellins are senescence-repressing hormones with active forms that decline in leaves as they age, whereas ethylene and ABA levels increase in senescing leaves and are considered senescence-promoting hormones that accelerate leaf and inflorescence senescence (Taiz et al., 2018). There are many bioactive GAs in plants, but we chose to focus on gibberellic acid $3\left(\mathrm{GA}_{3}\right)$ because this is a commercially available plant hormone that can

\begin{tabular}{llll}
\hline $\begin{array}{l}\text { Units } \\
\text { To convert U.S. to SI, } \\
\text { multiply by }\end{array}$ & U.S. unit & SI unit & $\begin{array}{l}\text { To convert SI to U.S., } \\
\text { multiply by }\end{array}$ \\
\hline 29,574 & $\mathrm{fl} \mathrm{oz}$ & $\mu \mathrm{L}$ & $3.3814 \times 10^{-5}$ \\
29.5735 & $\mathrm{fl} \mathrm{oz}$ & $\mathrm{mL}$ & 0.0338 \\
0.3048 & $\mathrm{ft}$ & $\mathrm{m}$ & 3.2808 \\
2.54 & inch $(\mathrm{es})$ & $\mathrm{cm}$ & 0.3937 \\
25.4 & inch $(\mathrm{es})$ & $\mathrm{mm}$ & 0.0394 \\
1 & $\mu \mathrm{mho} / \mathrm{cm}$ & $\mu \mathrm{\mu} \cdot \mathrm{cm}^{-1}$ & 1 \\
28.3495 & $\mathrm{oz}$ & $\mathrm{g}$ & 0.0353 \\
28,350 & $\mathrm{oz}$ & $\mathrm{mg}$ & $3.5274 \times 10^{-5}$ \\
1 & $\mathrm{ppm}$ & $\mathrm{mg} \cdot \mathrm{L}^{-1}$ & 1 \\
1 & $\mathrm{ppm}$ & $\mu \mathrm{\mu g} \cdot \mathrm{g}^{-1}$ & 1 \\
1 & $\mathrm{ppm}$ & $\mu \mathrm{L} \cdot \mathrm{L}^{-1}$ & 1 \\
$\left({ }^{\circ} \mathrm{F}-32\right) \div 1.8$ & ${ }^{\circ} \mathrm{F}$ & ${ }^{\circ} \mathrm{C}$ & \\
& & &
\end{tabular}


be applied to moderate plant growth and flowering, and it has been heavily investigated (Campos-Rivero et al., 2017; Hackett and Sachs, 1967; Taiz et al., 2018).

Leaf senescence is enhanced by the plant hormones ethylene and ABA (Taiz et al., 2018). Bending shoots of 'Taipei Red' bougainvillea resulted in greater ethylene production, leading to enhanced inflorescence number (Liu and Chang, 2011a). In a follow-up study, application of ethephon, a synthetic ethylene-releasing compound, to vegetative 'Taipei Red' bougainvillea shoots produced more inflorescences than vegetative control plants. However, foliar applications of ethephon to flowering shoots caused inflorescence and bud drop (Liu and Chang, 2011b). Unfortunately, Liu and Change (201la, 201 lb) only investigated one rate of ethephon $(0.15 \mathrm{mg} /$ plant) and did not measure changes in endogenous GA levels. They suggested that adequately controlling the response to ethylene during shoot development would facilitate inflorescence control.

In a preliminary study, we observed that the application of ethephon at rates of 0.07 to $0.15 \mathrm{mg} /$ plant to 'Afterglow' bougainvillea grown under SD conditions increased the number of inflorescences after 30 $\mathrm{d}$, but had limited success in improving inflorescence number under LD conditions (Chng and Moore, 2018). Ethephon rates of $0.3 \mathrm{mg} /$ plant applied to plants grown under both SD and $\mathrm{LD}$ conditions resulted in complete defoliation $3 \mathrm{~d}$ after treatment (Chng and Moore, 2018). The objective of this study was to monitor differences in inflorescence number and endogenous $\mathrm{GA}_{3}$ levels in response to the application of five rates of ethephon and ABA to LD plants.

\section{Materials and methods}

On 1 Oct. 2016, 65 rooted cuttings of 'Afterglow' bougainvillea were grown in a greenhouse in 4 -inch pots filled with $100 \% 5$-mm coarse aquarium zeolite (Pentair Aquatic Eco-systems, Apopka, FL). Zeolite was used to minimize potential flowering in response to drought or environmental stress because it holds moisture better than perlite, and was sterile and chemically inert (Liu and Chang, 201la, 2011b; Ma and Gu, 2012).
At planting, 'Afterglow' bougainvillea were fertilized with $10 \mathrm{mg} \cdot \mathrm{L}^{-1}$ of nitrogen (Peters Professional Bloom Booster 10N-13.5P-16.6K; JR Peters, Allentown, PA). We continued to apply the fertilizer at the same rate once per week throughout the remainder of the experiment. Plants were watered with $50 \mathrm{~mL}$ tap water [electrical conductivity $=516 \mu \mathrm{S} \cdot \mathrm{cm}^{-1}$, $\mathrm{pH}=8.3$ ] every $2 \mathrm{~d}$.

On 14 Oct. 2016, plants were actively growing, with some plants showing signs of inflorescence initiation. To ensure that all plants were at the same physiological state before treatment, all plants were sprayed with $1.2 \mathrm{mg} /$ plant of ethephon (Florel; Monterey Lawn and Garden Products, Fresno, CA) to induce leaf and inflorescence senescence. All plants were single stems that were pruned to remove the apical bud and to reduce plants to a mean height of 5 inches with seven visible lateral nodes.

Plants were kept vegetative for 3 weeks under LD conditions by supplementing the natural daylight (around $11 \mathrm{~h}$ ) with white light-emitting diode lights supplying $70 \mu \mathrm{mol} \cdot \mathrm{m}^{-1} \cdot \mathrm{s}^{-1} \mathrm{pho}-$ tosynthetic photon flux, measured using a handheld quantum meter (Apogee Instruments, Logan, UT). After 3 weeks (4 Nov. 2016), new growth had formed from existing buds, creating denser plants without increasing overall height. Plants were ready for treatments on 5 Nov. 2016. All plants except a control group of five replicate plants continued to receive supplemental lighting for the duration of the experiment. Plants that served as controls were covered with a black plastic 5 -gal container from 4:00 PM to 8:00 AM to create a SD photoperiod.

Plants grown under LD conditions were treated once either with ethephon (Florel) or ABA (ProTone; Valent Biosciences, Libertyville, IL). Ethephon was applied as a foliar spray of $0,0.05,0.07,0.10,0.15$, or 0.20 $\mathrm{mg} /$ plant. ABA was applied as a soil drench of $0,1,1.5,3,5,8$, or $10 \mathrm{mg} /$ plant. Each treatment rate contained five replicates (i.e., five individual potted plants).

The plants were arranged in a completely randomized design in an open-sided greenhouse exposed to ambient average air temperatures $\left(80 / 64{ }^{\circ} \mathrm{F}\right.$ day/night $)$ and $76.0 \%$ relative humidity $(\mathrm{RH})$ at the University of Florida, Fort Lauderdale
Research and Education Center, Davie, FL. Weather data were collected by the Florida Automated Weather Network system located $3 \mathrm{~m}$ from the greenhouse. This experiment was repeated to confirm results with 65 'Afterglow' rooted cuttings placed in the greenhouse on 3 Dec. 2016; defoliation on 17 Dec. 2016; and treatments on 7 Jan. 2017. Average temperatures and $\mathrm{RH}$ were similar in the repeat of the experiment.

Inflorescences on each plant were counted $48 \mathrm{~d}$ after treatment (23 Dec. 2016 and 24 Feb. 2017). Based on previous experiments, inflorescence appearance on 'Afterglow' bougainvillea occurred from 30 to $48 \mathrm{~d}$ after initiating conditions conducive to flowering (Chng and Moore, 2016, 2018). One inflorescence was defined as an individual thorn-inflorescence axil, regardless of how many florets were attached to the peduncle.

GA Determination. The levels of $\mathrm{GA}_{3}$ in the leaf tissue were determined using an adapted version of the spectrophotometric method developed by Holbrook et al. (1961) and further modified by Berríos et al. (2004). Chemicals and reagents used were zinc acetate solution [21.9 g zinc acetate (Acros Organics, Fair Lawn, $\mathrm{NJ}$ ) dissolved in deionized (DI) water and $1 \mathrm{~mL}$ glacial acetic acid (Thermo Fisher Scientific, Waltham, MA) made up to $100 \mathrm{~mL}$ ]; potassium ferrocyanide solution [10.6 g analytical-grade potassium ferrocyanide (Acros Organics) dissolved in $100 \mathrm{~mL}$ DI water]; dilute hydrochloric acid $(\mathrm{HCl})$ 35\% (Thermo Fisher Scientific); and $\mathrm{GA}_{3}$ standard [analytical-grade $\mathrm{GA}_{3}$ (Acros Organic)] dissolved in ethanol (Thermo Fisher Scientific) at various concentrations for calibration].

Fresh tissue was harvested from plants, and $200 \mathrm{mg}$ from each replicate was weighed and homogenized in $0.5 \mathrm{~mL}$ methanol, then centrifuged at $6000 g_{\mathrm{n}}$ for $3 \mathrm{~min}$. The extract was transferred to a glass vial to which 1 $\mathrm{mL}$ ethanol and $1 \mathrm{~mL}$ DI water was added, followed by $1 \mathrm{~mL}$ zinc acetate solution, and the mixture was shaken vigorously and left to stand for $2 \mathrm{~min}$ at room temperature. One milliliter of the potassium ferrocyanide solution was then added to the mixture and vortexed for $10 \mathrm{~s}$, then left to stand for $10 \mathrm{~min}$ and vortexed for 
another $10 \mathrm{~s}$. The resulting precipitate was filtered using filter paper (P8, Thermo Fisher Scientific); the clear extract was retained for analysis. A $500-\mu \mathrm{L}$ sample of the extract was transferred into a test tube. When the sample was ready to be analyzed, $800 \mu \mathrm{L}$ dilute $\mathrm{HCl}$ was added to the test tube, which was then shaken vigorously and pipetted into a quartz cuvette to be analyzed in the ultraviolet spectrophotometer (Cary 100; Varian, Palo Alto, CA), with absorbance measured at $254 \mathrm{~nm}$ over 2 $\mathrm{min}$. The differentials of the resulting curves were measured against a calibration curve constructed before the experiment using known concentrations of $\mathrm{GA}_{3}$ standard solutions of $0.125,0.25,0.5$, and $1.0 \mu \mathrm{L} \cdot \mathrm{L}^{-1}$. The resulting quotient is the concentration of $\mathrm{GA}_{3}$ in the sample.

Tissue samples for GA analysis were collected $\mathrm{l}$ and $48 \mathrm{~d}$ after treatment. Difference in $\mathrm{GA}_{3}$ was calculated as $\Delta \mathrm{GA}_{3}=\mathrm{GA}_{3 \mathrm{~d} 48}-\mathrm{GA}_{3 \mathrm{dl}}$. We pooled the analyses for the two runs of this experiment to get 10 replications to determine $\Delta \mathrm{GA}_{3}$. A correlation analysis between number of inflorescences per plant and $\Delta \mathrm{GA}_{3}$ was performed to look for a relationship between $\Delta \mathrm{GA}_{3}$ and inflorescence number in LD plants. The correlation analysis was performed separately for the ethephon and ABA treatments.

All statistical analyses were performed using the R statistical software package (R Foundation for Statistical Computing, Vienna, Austria). Differences in inflorescence number and $\Delta \mathrm{GA}_{3}$ among the 13 treatments were analyzed using analysis of variance (ANOVA) with mean separation using Tukey's honestly significant difference test. The experiment was repeated to confirm results. We ran an ANOVA to compare the two sets of data and decided to pool the data after finding no differences between the two runs of the experiment $(P<$ $0.220)$.

\section{Results and discussion}

'Afterglow' bougainvillea plants grown under SD conditions had more inflorescences than plants grown under LD conditions [9.6 vs. 1.8 , respectively; $P<0.01$ (Table 1 )]. 'Raspberry Ice' (Bougainvillea glabra), 'Taipei Red', 'Rainbow Gold', and 'San Diego Red' also had more inflorescences under SD conditions than LD conditions (Even-Chen et al., 1979; Liu and Chang, 2011b; $\mathrm{Ma}$ and $\mathrm{Gu}, 2012$; Norcini et al., 1992). However, photoperiod is only one trigger for inflorescence number in bougainvillea.

Bougainvillea will eventually produce inflorescences under LD conditions in response to other environmental cues such as temperature, light intensity, and irrigation, as well as in response to PGRs (Hackett and Sachs, 1985; Karagüzel, 1999; Liu and Chang, 201lb; Norcini et al.,
1992, 1994). 'Afterglow' plants grown under LD conditions and treated with ethephon at $0.05 \mathrm{mg} /$ plant had inflorescence numbers (10.6) similar to SD control plants (9.6) (Table 1). Both were greater than the LD control (1.8). As ethephon rate applied to LD plants increased from 0.05 to $0.10 \mathrm{mg} /$ plant, the number of inflorescences decreased, with fewer inflorescences than the LD control at rates of 0.10 , 0.15 , and $0.20 \mathrm{mg} /$ plant (Table 1 ). We did not observe any leaf drop at these ethephon rates.

However, we observed $100 \%$ leaf loss on LD plants $4 \mathrm{~d}$ after treatment with $A B A$ at rates of 6,8 , and $10 \mathrm{mg} /$ plant. At ABA rates of $1 \mathrm{mg} /$ plant, we observed inflorescence numbers similar to the LD control, with less inflorescences as rates increased (Table $\mathrm{l}$ ). 'Afterglow' plants that lost all leaves were slow to recover. Inflorescence development in bougainvillea might be a function of leaf number (Ramina et al., 1979; Tse et al., 1974). Young leaves were reported to be a source of GAs that stimulated sinks competing with developing inflorescences for resources (Hackett and Sachs, 1985; Tse et al., 1974). Research supports that GA is an inhibitor of inflorescence development in bougainvillea (Even-Chen et al., 1979; Hackett and Sachs, 1985; Norcini et al., 1992, 1994), and the application of PGRs that inhibit GAs promote inflorescence number in bougainvillea (Karagüzel, 1999; Liu

Table 1. Mean number of inflorescences and mean difference in gibberellic acid $\left(\triangle G A_{3}\right)$ of 5-inch (12.7-cm) 'Afterglow' bougainvillea plants grown in a greenhouse in 4 -inch $(10.2-\mathrm{cm})$ pots filled with coarse aquarium zeolite and subjected to short-day $(8 \mathrm{~h})$ or long-day $(14 \mathrm{~h})$ photoperiods in Fort Lauderdale FL. Long day plants were treated once with ethephon or abscisic acid (ABA). Ethephon was applied as a foliar spray of 0, 0.05, 0.07, 0.10, 0.15, or 0.20 mg/plant. ABA was applied as a soil drench of at $0,1,1.5,3,5,8$, or $10 \mathrm{mg} /$ plant. $^{\mathrm{z}}$

\begin{tabular}{|c|c|c|c|c|}
\hline Photoperiod & Chemical & Rate $(\mathrm{mg} / \text { plant })^{\mathrm{z}}$ & Inflorescences $[\text { mean } \pm \text { SE }(\text { no. })]^{\mathrm{y}}$ & $\Delta \mathbf{G A}_{3}\left[\text { mean } \pm \operatorname{SE}\left(\mu \mathrm{g} \cdot \mathrm{g}^{-1}\right)\right]^{\mathrm{y}, \mathrm{x}}$ \\
\hline Short day & None & 0 & $10.6 \pm 0.11 \mathrm{a}^{\mathrm{w}}$ & $-1.09 \pm 0.19 \mathrm{a}$ \\
\hline Long day & None & 0 & $1.0 \pm 0.12 \mathrm{c}$ & $-0.09 \pm 0.15 c$ \\
\hline Long day & Ethephon & 0.07 & $5.2 \pm 0.15 b$ & $-0.28 \pm 0.11 \mathrm{~b}$ \\
\hline Long day & Ethephon & 0.10 & $0.5 \pm 0.15 \mathrm{~d}$ & $0.30 \pm 0.18 \mathrm{~d}$ \\
\hline Long day & Ethephon & 0.15 & $0.4 \pm 0.10 \mathrm{~d}$ & $0.28 \pm 0.13 \mathrm{~d}$ \\
\hline Long day & $\mathrm{ABA}$ & 1.5 & $0.3 \pm 0.12 \mathrm{~d}$ & $0.29 \pm 0.18 \mathrm{~d}$ \\
\hline Long day & $\mathrm{ABA}$ & 3 & $0.4 \pm 0.10 \mathrm{~d}$ & $0.27 \pm 0.15 \mathrm{~d}$ \\
\hline Long day & $\mathrm{ABA}$ & 5 & $0.0 \pm 0.0 \mathrm{~d}$ & $0.69 \pm 0.11 \mathrm{e}$ \\
\hline Long day & $\mathrm{ABA}$ & 8 & $0.0 \pm 0.0 \mathrm{~d}$ & $0.70 \pm 0.13 \mathrm{e}$ \\
\hline Long day & $\mathrm{ABA}$ & 10 & $0.0 \pm 0.0 \mathrm{~d}$ & $0.77 \pm 0.19 \mathrm{e}$ \\
\hline
\end{tabular}

\footnotetext{
${ }^{\mathrm{z}} 1 \mathrm{mg}=3.5274 \times 10^{-5} \mathrm{oz}$.
}

${ }^{y}$ Values are means of 10 replicates. Results were pooled for both runs of this experiment.

${ }^{\mathrm{x}} \Delta \mathrm{GA}_{3}=\mathrm{GA}_{3 \mathrm{~d} 48}-\mathrm{GA}_{3 \mathrm{~d} 1} ; \mathrm{l} \mu \mathrm{g} \cdot \mathrm{g}^{-1}=1 \mathrm{ppm}$.

${ }^{\mathrm{w}}$ Means followed by the same lowercase letter within a column are not significantly different by Tukey's honestly significant difference test at $\alpha=0.05$ 
and Chang, 2011b; Norcini et al., 1994).

Short day control 'Afterglow' plants had a greater decrease in $\Delta \mathrm{GA}_{3}$ over $48 \mathrm{~d}$ than LD control plants (Table 1). 'Afterglow' plants treated with ethephon at $0.05 \mathrm{mg} /$ plant had a decrease of $\Delta \mathrm{GA}_{3}$ similar to the SD control. Only 'Afterglow' plants treated with $\mathrm{ABA}$ at $1 \mathrm{mg} /$ plant had a decrease in $\Delta \mathrm{GA}_{3}$, which was similar to the LD control (Table 1). The number of 'Afterglow' inflorescences and $\Delta \mathrm{GA}_{3}$ correlated negatively for both ethephon (correlation coefficient $=-0.915, P=$ 0.011 ) and ABA (correlation coefficient $=-0.885, P=0.046)$ treatments. In spinach (LD plant), GA levels were low in plants when they were grown under SD conditions, and plants maintained a rosette form (Metzger and Zeevaart, 1980; Taiz et al., 2018). However, when spinach plants were moved to LDs, GA levels increased and resulted in flowering, suggesting that GA metabolism was affected by daylength (Metzger and Zeevaart, 1980; Taiz et al., 2018).

The application of ethephon to vegetative shoots of 'Taipei Red' increased l-aminocyclopropane1-carboxylic acid (ACC) contents, a precursor to ethylene, which increased ethylene production and accelerated maturation of shoots, improving flowering (Liu and Chang, 2011b). Reproductive shoots also had greater ACC contents than vegetative shoots, suggesting that factors that increase ACC synthesis such as drought or application of ethephon improve flowering. However, excess ethylene in reproductive shoots led to inflorescence and leaf drop (Liu and Chang, 2011b). Greater ethylene production was associated with earlier maturing and flowering when shoots of bougainvillea were bent (Liu and Chang, 201 la, 2011b). Ethylene and ABA are regarded as senescencepromoting and stress-produced hormones, and their levels tend to increase as plants age (Taiz et al., 2018). However, GAs are senescence-repressing hormones and their levels decline as leaves age (Taiz et al., 2018). In our study, the application of low rates of ethephon and ABA to LD 'Afterglow' plants resulted in a decrease in $\mathrm{GA}_{3}$ and at least one inflorescence.

Our results suggest that the use of ethephon and $\mathrm{ABA}$ at low rates might be another tool for improving inflorescence number in 'Afterglow' bougainvillea when other PGRs are unavailable or when light levels, temperature, irrigation, and daylength are harder to manage. It is apparent that inflorescence control in bougainvillea involves multiple cues that vary with cultivar and the environment in which they are grown, and will require more study to link the many variables into an accurate inflorescence model.

\section{Literature cited}

Berríos, J., A. Illanes, and G. Aroca. 2004. Spectrophotometric method for determining gibberellic acid in fermentation broths. Biotechnol. Lett. 26:67-70.

Campos-Rivero, G., P. Osorio-Montalvo, R. Sanchez-Borges, R. Us-Camas, F. Duarte-Ake, and C. Del-la-Pena. 2017. Plant hormone signaling in flowering: An epigenetic point of view. J. Plant Physiol. 214:16-27.

Chng, M.W. and K.A. Moore. 2016. Optimal photoperiod treatment for flowering of Bougainvillea ×buttiana 'Afterglow'. Proc. Florida State Hort. Soc. 129:231-233.

Chng, M.W. and K.A. Moore. 2018. Effects of plant growth regulators ethephon and s-ABA on flowering of Bougainvillea $\times$ buttiana 'Afterglow' under different photoperiods. Acta Hort. 1205:431-436.

Even-Chen, Z., R.M. Sachs, and W.P. Hackett. 1979. Control of flowering in Bougainvillea 'San Diego Red': Metabolism of benzyladenine and the action of gibberellic acid in relation to short day induction. Plant Physiol. 64:646-651.

Hackett, W.P. and R.M. Sachs. 1967. Chemical control of flowering in Bougainvillea 'San Diego Red'. Proc. Amer. Soc. Hort. Sci. 90:361-364.

Hackett, W.P. and R.M. Sachs. 1985. Bougainvillea, p. 38-47. In: A.H. Halevy (ed.). Handbook of flowering. Vol. II. CRC Press, Boca Raton, FL.
Holbrook, A.A., W.J.W. Edge, and F. Bailey. 1961. Spectrophotometric method for determination of gibberellic acid, $\mathrm{p}$. 159-167. In: R.F. Gould (ed.). Gibberellins. American Chemical Society, Washington, DC.

Karagüzel, O. 1999. Effects of paclobutrazol on growth and flowering of Bougainvillea spectabilis Willd. Turk. J. Agr. For. 23:527-532.

Liu, F.Y. and Y.S. Chang. 2011 la. Effects of shoot bending on ACC content, ethylene production, growth, and flowering of bougainvillea. Plant Growth Regulat. 63:37-44.

Liu, F.Y. and Y.S. Chang. 2011b. Ethephon treatment promotes flower formation in bougainvillea. Bot. Stud. 52:183-189.

Ma, S. and M. Gu. 2012. Effects of water stress and selected plant growth retardants on growth and flowering of 'Raspberry Ice' bougainvillea (Bougainvillea spectabilis). Acta Hort. 937:237-242.

Metzger, J.D. and J.A.D. Zeevaart. 1980. Effect of photoperiod on the levels of endogenous gibberellins in spinach as measured by combined gas chromatography-selected ion current monitoring. Plant Physiol. 66:844-846.

Norcini, J.G., J.H. Aldrich, and J.M. McDowell. 1994. Flowering response of Bougainvillea cultivars to dikegulac. HortScience 29:282-284.

Norcini, J.G., J.M. McDowell, and J.H. Aldrich. 1992. Effect of dikegulac on Bougainvillea flowering under increasing and decreasing daylength. HortScience 27:634.

Ramina, A., W.P. Hackett, and R.M. Sachs. 1979. Flowering in bougainvillea a function of assimilate supply and nutrient diversion. Plant Physiol. 64:810-813.

Taiz, L., E. Zeiger, I.M. Moller, and A. Murphy. 2018. Plant physiology and development. 6th ed. Sinauer Associates, Sunderland, MA.

Talon, M. and J.A.D. Zeevaart. 1990. Gibberellins and stem growth as related to photoperiod in Silene armeria L. Plant Physiol. 92:1094-1100.

Tse, A.T.Y., A. Ramina, W.P. Hackett, and R.M. Sachs. 1974. Enhanced inflorescence development in Bougainvillea 'San Diego Red' by removal of young leaves and cytokinin treatments. Plant Physiol. 54:404-407. 